\title{
CRESCENDO EM CATINGUEIRA: CRIANÇA, FAMÍLIA E ORGANIZAÇÃO SOCIAL NO SEMIÁRIDO NORDESTINO
}

Flávia F. Pires

— Pai, quando o senhor achar que eu posso, eu venho também ajudar o senhor capinar roça...

Pai não respondia nada. Miguiliam tinha medo ter falado bobagem faltando ao respeito (Guimarães Rosa, Corpo de baile, 1956).

\section{Introdução}

Este é um artigo etnográfico que tem como objetivo apresentar as crianças catingueirenses, destacando aspectos da sua vida social e familiar, através do desvelamento das contingências cotidianas enfrentadas por elas, assim como expor as expectativas adultas em relação a elas. Nesse sentido, tanto quanto sobre as crianças catingueirenses, este artigo é sobre a infância catingueirense, seus constrangimentos e também sua reinvenção permanente. Para isso, minha estratégia é lançar luz principalmente sobre o debate em torno da socialização e do trabalho infantis a partir do entendimento das crianças como objetos de diversão e da infância como período de aprendizado moral para o grupo estudado. Ao fazê-lo, tornamse explícitos os inúmeros papéis que as crianças desempenham na vida familiar e comunitária e sua importância crucial para a reprodução social das famílias e da comunidade.

A primeira parte do artigo trata de pensar as crianças pequenas por meio de três memórias etnográficas: um evento na igreja envolvendo uma criança de 3 anos, o ritual de apresentação dos novos membros à comunidade e o cortejo fúnebre de um anjinho. Na segunda parte do artigo apresento o cotidiano familiar, especialmente os cuidados na manutenção da unidade doméstica. Na terceira parte do texto contemplo duas questões: a primeira sobre o trabalho infantil, sobretudo doméstico, e a segunda sobre o entendimento da infância como período de aprendizado moral. 
Resultado de uma pesquisa de campo sobre as experiências religiosas locais, realizada principalmente entre os anos de 2000 e 2005, este artigo beneficia-se da observação participante como método de pesquisa primordial. No entanto, inspirada nos trabalhos de Toren (1999), também utilizei redações de crianças como estratégia complementar de produção de dados etnográficos (Pires 2011a, 2007). O estudo aqui apresentado tem como pressuposto incluir as crianças na pesquisa antropológica como forma de ter acesso a um entendimento da realidade social muitas vezes diferenciado mas, ao mesmo tempo, negligenciado pelos pesquisadores. Embora "Não $\mathrm{h}$ [aja] nenhuma razão para nos focarmos nas crianças às expensas dos adultos" (Toren 2002:118-9), o que propomos é incluir as crianças nas pesquisas antropológicas como objetos de análise, interlocutores e sujeitos, sem com isso excluir os adultos.

Catingueira, o município onde a pesquisa teve lugar, é uma cidadezinha do sertão da Paraíba com menos de 5.000 habitantes, cuja população, com fortes raízes camponesas, não encontrando meios de sobrevivência digna na localidade, emigra em quantidades consideráveis para outras cidades do país. Se bem sucedidos nessa espécie de "diáspora nordestina", tornarse-ão "filhos ausentes", categoria social altamente prestigiosa, que indica sucesso na penosa aventura de desterritorialização ${ }^{1}$ e a acumulação de um capital social que os distinguirá dos que ficaram, mas que ao mesmo tempo demanda constantes visitas e remessas financeiras (Pires 2008, 2011b; Deleuze \& Guattari 1995-1997). Os catingueirenses, na sua maioria, são católicos, embora haja um número crescente de neopentecostais e um centro espírita kardecista em funcionamento desde 1979. A festa de São Sebastião, padroeiro de Catingueira, toma a cidade a cada janeiro, revelando um ritmo particular na morfologia social (Mauss 1974; Pires 2011b). As crianças têm acesso ao ensino fundamental e médio no próprio município, mas os jovens precisam migrar ou realizar deslocamentos diários para cursar a universidade. A cidade é terra do famoso repentista Inácio da Catingueira, motivo de orgulho para a população.

De fato, Clifford (1998) tem razão: a natureza do relato etnográfico e a produção do conhecimento antropológico muitas vezes congelam os povos estudados em um tempo pretérito. O presente etnográfico - recurso utilizado ao longo deste texto - através de memórias etnográficas que são trazidas à baila, contribui para esse efeito de congelamento dos dados. Ciente desse problema, mas diante da impossibilidade de encontrar outra narrativa menos comprometedora, gostaria de salientar que os dados aqui apresentados foram observados no início da última década e, também por isso, acabam por soar, em alguns momentos, anacrônicos. Isto se deve, acredito, à velocidade com 
que os modos de vida das crianças catingueirenses têm sido modificados, tanto em virtude da historicidade inerente às sociedades, para lembrar LéviStrauss (1952), quanto por influência dos esforços massivos que vêm sendo feitos em todo o Brasil para lidar com questões como o trabalho infantil e o acesso à escola. Programas como o PETI (Programa de Erradicação do Trabalho Infantil), o Bolsa Escola e notadamente o Bolsa Família impactaram enormemente a vida das crianças aqui descritas, principalmente no que diz respeito à escolarização e ao acesso a bens de consumo e serviços (Pires 2009). Em todo o texto são cotejadas crianças em contextos etnográficos que extrapolam Catingueira. Este recurso, que pode parecer argumento de autoridade científica, justifica-se na medida em que o objetivo aqui é não exotizar a infância catingueirense, mas favorecer mediações. Não estou sugerindo, no entanto, uma universalização da categoria criança, antes pelo contrário, a ideia é suscitar a comparação entre formas possíveis de socialização infantil. Se há, no entanto, alguma universalidade a ser reclamada, ela diz respeito ao papel crucial, mas largamente negligenciado pela antropologia, que as crianças desempenham na reprodução social das suas famílias e comunidades.

\section{A criança pequena}

O primeiro episódio etnográfico ao qual me reporto aconteceu no ano de 2005 durante a missa de sétimo dia pelo falecimento do jovem vice-prefeito, que morrera tragicamente num acidente automobilístico. A atmosfera dentro da igreja era solene e pesarosa. Uma criança de aproximadamente 3 anos de idade ligou um daqueles brinquedos que imitam os diferentes toques de um celular. Ao contrário da minha expectativa, ao invés de repreender a criança, seus pais, especialmente a mãe, começaram a sorrir, como se estivessem orgulhosos do filho. Ela olhou para os lados convidando toda a gente, que se comprimia dentro da igreja cheia, a apreciar o momento, como se se tratasse de um espetáculo. E, de fato, as pessoas ao redor começaram a sorrir, entreolhando-se, balançando afirmativamente a cabeça, aprovando a atitude do pequeno. Não percebi nenhum sinal de desconforto pelo barulho que a criança fazia.

Há, de modo geral, uma grande condescendência em relação às birras e aos choros infantis, principalmente quanto às meninas. Isto dura até mais ou menos os 5 anos de idade, quando atitudes como estas começam a ser desencorajadas. É comum os meninos serem tratados com mais rigor que as meninas, e espera-se que sejam mais fortes e demonstrem menos as suas 
fragilidades (como chorar). Por diversas vezes, observei as reuniões religiosas infantis - que são o catecismo e a reunião da Infância Missionária para os católicos; a reunião dominical para os evangélicos; e a reunião das crianças, no caso do espiritismo - serem interrompidas para se dar atenção àquela criança pequena que caíra, chorara, ou simplesmente fizera algo considerado "mimoso". Da mesma forma, notei que quanto mais nova a criança é, mais carinhoso é o cuidado com ela — assim como este cuidado é mais tolerado com as crianças do sexo feminino em detrimento daquelas do sexo masculino. Demonstrações de carinho para com meninos só são observadas enquanto ele ainda é muito pequeno, no máximo, até cerca dos 5 anos de idade.

A segunda memória de campo é uma espécie de ritual de apresentação dos recém-nascidos à comunidade, no qual um papel central é desempenhado por meninas semipúberes ou púberes. Muitas vezes estava na minha casa e aparecia uma menina (em algumas ocasiões, acompanhada por uma amiga) carregando um bebê nos braços. A menina vinha "mostrar" a mim o bebê da vizinha, da prima ou da irmã. É muito comum ver os bebês circulando pela cidade nos colos de meninas e, quando isto acontece, geralmente esboça-se um elogio - mas não muito entusiasmado, porque o elogio é uma maneira comum de se colocar mau-olhado. ${ }^{2}$ Depois, se pergunta de quem é aquele bebê. Com esta pergunta, o que se quer, de fato, é saber quem é a mãe, como se, ao se saber quem é a mãe, o pai logo pudesse ser identificado de imediato. Se a pessoa não identificar imediatamente os pais do bebê, a menina dará mais informações sobre eles, por exemplo (e geralmente nessa ordem), de quem são filhos, quem são os seus vizinhos, onde ou com quem trabalham. Identificados os pais do bebê, a conversa mirra. A menina, por sua vez, vai à outra casa "mostrar" o bebê, até que ela se canse ou o bebê apresente comportamento inadequado, como começar a chorar ininterruptamente.

Em Catingueira, um bebê vai com facilidade para os braços de outras pessoas que não são da própria família ou responsáveis diretos pelo seu cuidado. No entanto, um bebê não é visto nos braços de qualquer um. São geralmente meninas, na faixa etária dos 9 aos 13 anos de idade, que circulam pelas casas mostrando os bebês, ou seja, meninas novas demais para serem mães, e velhas demais para brincarem de bonecas. Esta menina - é importante ressaltar - é uma conhecida da família. Ela pode ser uma parenta, mesmo que distante, como uma prima de terceiro grau, ou mesmo uma vizinha, ou seja, ela é "de confiança". O fato é que os bebês, mesmo bem pequenos (com um mês), já "passeiam" pela cidade sem a companhia de seus respectivos pais. Quiçá a propriedade das crianças seja compartilhada tanto pela comunidade quanto por seus pais. Por uma via heterodoxa, chegamos a um tipo de sociedade similar à que existe nos países nórdicos 
e que permite, por exemplo, o trabalho do sociólogo Jens Qvrotrup (2005), cujo pressuposto básico é que o cuidado das crianças não deve se limitar aos seus pais, mas sim ser responsabilidade da sociedade como um todo, embora o autor enfatize o papel do Estado no cuidado das crianças.

Outro dado interessante é que o bebê é acordado sem dó para que possa ser apreciado - principalmente se tiver os olhos claros. A menina que carrega o bebê vai fazer de tudo para que ele acorde quando o estiver mostrando, como bater de leve na sua bochecha, sacudi-lo, chamar seu nome em voz alta perto do seu ouvido. Desta forma, a vontade dos bebês parece estar submetida à vontade dessas meninas e à dos adultos. Ademais, mostrar os bebês implica divertimento para as meninas envolvidas na atividade, pois ele em suas mãos é como um brinquedo. Às vezes, elas são chamadas para tomar café ou comer um doce na casa por onde passam. ${ }^{3}$ Mas o simples fato de entrar em uma casa já é diversão suficiente para uma menina préadolescente ou adolescente.

Se, de um lado, é permitido "usar" as crianças mais novas como brinquedo, como também foi observado por Fortes (1938) entre os Talensi, de outro lado, a tarefa de "pajear" as crianças pequenas é geralmente destinada à irmã mais velha, o que também foi assinalado por Mead e Bateson (1942) em relação aos dados de Bali e por Toren (2010:26) quanto às crianças fijianas. A função pode ser exercida pelo irmão mais velho, no caso da falta de uma irmã em idade adequada para a tarefa. ${ }^{4}$ No entanto, é mais provável que ela seja executada por uma criança do sexo feminino: uma prima ou uma vizinha. O caso descrito acima, em que as meninas vão mostrar os bebês, pode ter lugar, por exemplo, na volta de uma visita regular ao posto de saúde, o que ressalta a responsabilidade das meninas mais velhas para com os bebês. Muitas vezes, é a presença dessas meninas que permite que a mãe de um bebê trabalhe fora de casa ou desempenhe outras funções remuneradas ou não, evidenciando os padrões de dependência da geração mais velha em face das gerações mais novas. É oportuno lembrar que Fortes (1938) e Schildkrout (1978), em textos hoje considerados clássicos, destacam as relações de dependência entre as gerações através das inúmeras atividades pelas quais as crianças são responsáveis, essenciais para a reprodução doméstica.

As crianças pequenas sempre acompanham os irmãos mais velhos ou, de forma mais constante, um deles, aquele que é responsável por elas. Assim, espera-se evitar que o irmão mais velho faça alguma coisa da qual esteja proibido e, ao mesmo tempo, que tome conta do irmão menor ou dos irmãos menores (Pires 2010). A respeito das crianças hausa, na Nigéria, Schildkrout afirma: "Os pais [...] especificamente delegam o cuidado das crianças mais jovens às mais velhas" ${ }^{5}$ (1978:124). Muitas vezes, essas 
crianças pequenas vão, por exemplo, para o catecismo, porque o irmão ou a irmã mais velho(a), responsável por elas, está se preparando para a primeira eucaristia, da mesma forma que "[a]s crianças pequenas que já sabem andar acompanham seus irmãos mais velhos para a escola Árabe", no caso das crianças hausa (Schildkrout 1978:125). A família aprova o fato de a criança pequena ir entrando em contato com as coisas da religião. No entanto, nem os pais, nem as outras crianças, nem as professoras esperam que ela entenda o que está sendo tratado no catecismo.

Das crianças pequenas não se exige que falem, rezem ou mesmo que se comportem bem nas reuniões de religião. Fato similar foi observado por Mayblin (2010:156) no agreste pernambucano, onde as crianças pequenas de Santa Rita têm acesso a uma liberdade maior se comparadas às crianças mais velhas. Isto se dá justamente porque as crianças pequenas, conforme afirma Fortes (1938), arrazoando a respeito das crianças talensi, ainda não adquiriram juízo (sense) — só depois de adquirirem juízo é que serão cobradas e eventualmente punidas. ${ }^{6}$ Chama a atenção a importância das crianças mais velhas na educação das mais novas e o fato de que elas aprendem com os seus pares. Nesse sentido, em Catingueira, como "[n]a sociedade Talensi, cada estudante torna-se, em algumas situações, um professor" (Fortes 1938:15), já que nessa sociedade "[d]a autoridade dos pais sobre a criança é derivada a autoridade do irmão mais velho sobre os mais jovens" (Fortes 1938:35). Em Catingueira, a criança mais velha pode e deve repreender as mais jovens, caso seja necessário.

O terceiro episódio de campo se deu no ano de 2000, quando segui o cortejo fúnebre de um anjinho, o pequeno Sebastião, um bebê falecido com apenas alguns dias de vida. As pessoas, de suas janelas, paravam o pequeno séquito e pediam que levassem o caixãozinho até elas. Queriam "olhar" o bebê morto. Era o próprio pai do anjinho quem o fazia. As pessoas olhavam o pequeno com dó e curiosidade e, às vezes, perguntavam: "morreu de quê?" (Pires 2003:13-14). Ter um anjinho no céu é tradicionalmente tolerado pelas famílias, como forma de se ter acesso privilegiado aos bens espirituais. A mãe se consola com a morte de um bebê pela certeza de ter alguém no céu a olhar por ela e pela família que ficou na terra. Scheper-Hughes (1992) viu neste fato certa condescendência em relação às mortes das crianças, conclusão da qual discordo, na medida em que esse consolo é uma forma de lidar com a dor da perda do bebê. Durante o trabalho de campo, pedi a Sara, uma menina de 12 anos de idade, que desenhasse o seu anjo da guarda. Ela desenhou a sua irmã, que morreu ainda bebê. Sara expressa carinhosamente o pesar de não tê-la conhecido e, ao mesmo tempo, a alegria de ter como anjo da guarda a sua própria irmã: 
O meu anjinho é a minha irmã. Ela morreu, mas ela vai ser sempre a minha irmã e o meu anjo. Ela morreu quando ela era criança, deu uma disenteria, aí ela morreu. Eu era muito pequena, gostaria de ter conhecido ela. Adoraria muito conhecer ela, por isso escolhi ela. Eu adorei ela; mesmo que eu não [tivesse] conhecido, ela é o meu anjo.

Nesse subtópico sugeri que, assim como a criança pequena faz as vezes de "brinquedo" para as meninas no ritual de apresentação do novo membro à comunidade, ela também pode ser objeto de diversão para os adultos, que riem dela, como no episódio na igreja. Dinâmica parecida acontece em Tonga, onde "[d]esde o nascimento, as ações dos bebês são tratadas como performances" (Morton 1996:157), ou seja, as ações das crianças pequenas são entendidas como deliberadamente voltadas para divertir a plateia de adultos e crianças mais velhas.

Em Catingueira, as crianças pequenas não são consideradas capazes de compreensão do mundo, por isso não se espera que elas se comportem bem. Para Mayblin, as crianças pequenas de Santa Rita "[...] são percebidas como menos responsáveis pelos seus mal-feitos [...]" (2010:156), ou segundo Morton, “[o]s bebês [tonga] são valevale [...] literalmente tolos tolos" (1996:156). Em Catingueira, talvez por esta mesma incapacidade imputada às crianças pequenas, toda a gente reconheça graça e pureza nos seus gestos e nas suas palavras. Não é à toa que, se uma criança pequena morre, se acredita que ela vá diretamente para o céu. ${ }^{7}$ Ela "é um inocente", como se diz localmente, aquele que não possui pecados e não pode ou não deve ser punido. No entanto, para terminar este subtópico, o que gostaria de ressaltar, além do tom espetacular que a morte de um bebê adquire e a forma como as crianças, mesmo mortas, são expostas ao escrutínio dos adultos, são os inúmeros papéis desempenhados pelas crianças na vida familiar e comunitária, o que se dá mesmo após o seu falecimento.

\section{Cotidiano familiar}

Aos 5 ou 6 anos de idade, uma criança é chamada a assumir certas tarefas domésticas. No caso de meninas, constantemente elas são responsáveis por lavar "os troços", ou seja, a louça do almoço ou do jantar - por vezes, ambas. Principalmente em famílias pobres, elas também são responsáveis por lavar a sua própria roupa e, em algumas ocasiões, ajudar a mãe ou a irmã mais velha a lavar a roupa da família. Quando se trata de uma família pobre e numerosa, a roupa é lavada no açude, em geral pela mãe. Exceção ocorre quando ela se 
encontra enferma: neste caso, lavar a roupa da família passa a ser obrigação da irmã mais velha. Quando a família é pobre, mas pouco numerosa, a roupa pode ser lavada na própria casa, desde que se conte com água encanada e os meios de pagar a conta do fornecimento da água ao fim do mês. ${ }^{8}$ Outra tarefa das meninas é varrer e passar o pano ${ }^{9}$ na casa. Ainda, as meninas são chamadas para buscar água na nascente, no olho d'água ou no açude, com o auxílio de latas de tinta reutilizadas. No caso de crianças de 5 ou 6 anos, a lata para carregar a água é de proporções reduzidas. As mães costumam carregar a água nas latas cuja capacidade é de 20 litros, enquanto as crianças transportam a água nas latas de 5 litros. É importante lembrar que, como aponta Fortes (1938:48) em contexto etnográfico diverso, embora pequena, a contribuição da menina para manter o abastecimento de água da casa é real.

O serviço doméstico é feito o quanto antes possível, sempre na parte da manhã. Geralmente, a primeira tarefa é acender o fogo. A maioria das casas usa a lenha ou o carvão para cozinhar. Muitas casas têm fogão a gás, mas o preço do gás em botijão é tido como empecilho para o seu uso cotidiano. Em muitas casas o fogão a gás funciona como peça decorativa, às vezes colocado na sala, outras vezes na cozinha que fica dentro da casa, mas que não é usada. $\mathrm{O}$ fogão a gás não fica habitualmente perto do fogão a lenha ou carvão para evitar que a fumaça o torne inapelavelmente preto. Ter um fogão a gás, mesmo que não seja utilizado, é sinal de status social. A verdadeira cozinha, isto é, onde se faz a comida, fica do lado de fora da casa, num "puxadinho" ou numa espécie de tenda feita para comportar o fogão a lenha ou carvão. Nele, a comida é preparada, e ali as pessoas costumam comer no dia a dia. Acredita-se que a comida preparada no fogão a lenha seja mais saborosa e mais nutritiva.

Por fim, muitas casas usam uma espécie de estrutura de metal sustentada por um tripé, chamada de "fogareiro", para cozinhar. No fundo do tripé depositam o carvão. $\mathrm{O}$ fogareiro comporta apenas uma panela. O uso difundido do fogareiro justifica-se na medida em que não é incomum as famílias se alimentarem apenas de feijão com farinha. ${ }^{10} \mathrm{O}$ fogareiro é a maneira mais econômica de cozinhar, já que utiliza o combustível necessário para apenas uma panela. Como ele fica no chão, para ser capaz de manuseá-lo, a cozinheira adulta precisa abaixar-se, ficar de cócoras, mas no caso de uma criança (na faixa dos 10 anos de idade), a panela alcança a altura das mãos. Embora a altura da brasa seja fixa, em alguns desses fogareiros a altura da panela pode ser regulada, mantendo a comida quente - mas sem cozinhá-la demasiadamente. Em algumas casas usa-se para cozinhar apenas uma pilha de tijolos ou pedras no chão, em algum cantinho ao ar livre, mas protegido do vento e, igualmente, faz-se o fogo com carvão ou lenha. ${ }^{11}$ 
Por volta das 9 horas da manhã, a arrumação da casa já deve estar concluída para se começar a preparar o almoço, que ficará pronto entre 10 e 11 horas. Se há duas crianças do sexo feminino em uma família e crianças pequenas para se "pajear", a mãe encarregar-se-á do almoço, e as meninas ficarão incumbidas de cuidar dos irmãozinhos e do serviço da casa. De todas as atividades domésticas, a preparação da comida parece ser a última a ser estendida às crianças ou às adolescentes, permanecendo como atividade destinada à mulher casada. Por exemplo, numa família em que há apenas a mãe idosa, uma filha por volta dos 25 anos e um filho por volta dos 30 anos, a mãe será a cozinheira. A filha sabe muito bem como cozinhar, mas esta tarefa ficará a cargo da mãe - até que ela se torne inválida ou faleça. Como afirmo adiante, as meninas sempre se mostravam prontas para me ajudar na "luta"12 da casa, no entanto, nunca se ofereceram para cozinhar. Fazer a comida parece ser o serviço reservado às mães ou apenas ocasionalmente passado para as filhas.

Por volta dos 5 anos de idade, a criança deve começar a ir ao colégio a fim de se preparar para a primeira série do ensino fundamental - que começa por volta dos 6 anos. Se a família não valoriza sobremaneira a educação formal, a adaptação ao colégio não é forçada, postergando-se o início da vida escolar para o próximo ano. Sánchez aponta a respeito da sua pesquisa entre os Nahuas no México (2007:94) que "a maioria dos pais não considera a educação como um valor em si". Em Catingueira, acredita-se que não compensa forçar a criança pequena a fazer o que ela não quer. Talvez isto possa ser entendido lançando-se mão do que Mayblin (2010) assinala a respeito de Santa Rita, em que a primeira infância é tida como a melhor fase da vida e, no entanto, a mais curta, seu contraponto sendo a idade adulta, repleta de sofrimento e obrigações.

De modo geral, as famílias que valorizam a educação formal fazem questão de mandar os filhos o quanto antes para o colégio. É necessário ter, no mínimo, 3 anos de idade para ser aceito na escolinha chamada Sossego da Mamãe, que funciona em todos os dias úteis, com duração de uma hora e trinta minutos, como reforço escolar, pré-primário e creche. A classe é multisseriada, assim como os interesses, que são variados. Por exemplo, algumas crianças estão ali para fazer os deveres do colégio; outras, para aprender a ler; outras, porque estão atrasadas em relação ao conteúdo didático do colégio; outras ainda para começar a pegar o "gosto pelo lápis", como se diz em Catingueira. A "creche" é particular, mas funciona nas dependências do colégio municipal. Pagam-se R\$ 15 por aluno (dado do ano de 2005). O município de Catingueira e o estado da Paraíba proveem ensinos fundamental e secundário completos, como já salientei; mesmo assim, algumas famílias 
optam por mandar os filhos para escolas particulares em Patos, com vistas a uma educação de melhor qualidade. ${ }^{13}$

Neste subtópico apresentamos um pouco do cotidiano das famílias, principalmente no que diz respeito aos cuidados com a casa e ao início da vida escolar das crianças. Concordamos com Nieuwenhuys quando afirma que "[o]s filhos dos camponeses pobres se envolvem, em geral, em uma variedade de atividades que, embora raramente remuneradas, são necessárias para o sustento da família" (1994:9).

\section{Infância como período de trabalho e aprendizado moral}

Em Catingueira, as crianças de ambos os sexos, mas especialmente os meninos, são consideradas muito úteis para levar recados e informações — papel igualmente destacado por inúmeros pesquisadores em outros contextos etnográficos. Por exemplo, Cohn (2000) afirma que as crianças xikrin têm acesso às unidades familiares com muito mais facilidade que os adultos. Nunes (2002) destaca esse mesmo conhecimento nas crianças a 'uwe-xavante em função da sua permeabilidade na aldeia e, por esta vantagem, diz-se que "as crianças tudo sabem". A mesma possibilidade de entrar e sair das casas com liberdade é essencial na educação hausa, conforme discorre Schildkrout, "dadas as restrições de mobilidade espacial dos adultos [...]" (1978:124). Tal aspecto também foi destacado por Fortes entre os talensi (1938:53) e por Toren entre os fijianos (2010:25).

Em Catingueira, além de levar recados, as crianças são mandadas para realizar compras quando a família está em dia com a venda, o que também acontece em Fiji (Toren 2010:25), Tonga (Morton 1996:137) e Hausa (Schildkrout 1978:117). Geralmente, as compras nos mercadinhos não são pagas em espécie, independente de o comprador ser um adulto ou uma criança. O dono do mercadinho anota o valor gasto em uma caderneta, o qual deverá ser pago assim que a família receber o salário ou o benefício do governo federal a que tem direito. No caso de atraso do pagamento da conta do mercadinho, o chefe da família, a mãe ou o pai, de acordo com o capital social de que disponha (se o pai da família é tido como alcoólatra, a mãe é quem irá à venda), comparece para negociar o crédito e possibilitar a nova compra. Uma criança, em princípio, não poderia negociar crédito.

Segundo Morrow e Vennam (2010), em Andhra Pradesh, na Índia, as crianças do sexo masculino começam a trabalhar mais tarde que as meninas, porque seu trabalho é, em geral, feito fora da casa. Em Catingueira, embora concorde que o trabalho dos meninos esteja mais voltado para o universo da rua ou para as redondezas da casa (como colocar comida para os animais, 
capinar o quintal, buscar lenha, fazer compras, levar recados), não encontro meios de sustentar a afirmação de que eles trabalhem menos ou comecem a trabalhar mais tarde que as meninas. Por exemplo, em Catingueira, na falta de uma menina, os meninos podem ajudar a mãe ou a irmã mais velha nas tarefas domésticas consideradas femininas, conforme já apontado, como cuidar dos irmãos, ajudar a cozinhar, lavar e passar a roupa e lavar as louças.

Embora nunca tenha visto um garoto buscando água com os latões na cabeça, se a família possui um jumento ou uma carroça, a atividade de buscar água passa a ser essencialmente masculina, e por ela os meninos costumam ser responsáveis. Mesmo que seja raro, um rapaz que saiba "se virar" no caso de uma necessidade - isto é, que saiba cozinhar e tomar conta de uma casa - é apreciado como um futuro bom marido, principalmente pelas suas potenciais sogras. Apesar de meninos desempenhando papéis domésticos femininos também terem sido encontrados na literatura especializada em outros contextos etnográficos (Fortes 1938; Morton 1996; Schildkrout 1978), a possível existência e as características de uma divisão social do trabalho infantil doméstico é um tema estimulante para futuras pesquisas.

Em contrapartida, um menino acompanha seu pai ou irmão mais velho em atividades consideradas masculinas. ${ }^{14}$ Se o pai da família sai para pescar, é esperado que o garotinho o acompanhe, ajudando a carregar os instrumentos, observando-o e aprendendo a atividade. Um pai pode levar os filhos para auxiliá-lo quando sai para trabalhar na roça. Os filhos maiores adolescentes, por exemplo - são pagos pelo empregador de acordo com o salário corrente; já as crianças costumam ser pagas tendo em vista sua menor capacidade de produção. Crianças de 5 ou 6 anos não são contratadas, mas podem substituir o pai se ele estiver cansado, propiciando-lhe um tempo de descanso. Ainda, é uma criança, geralmente do sexo masculino, quem leva o almoço e a água do pai e dos irmãos mais velhos quando estão trabalhando na lavoura. Nesses momentos, a observação das atividades dos mais velhos favorece o aprendizado das crianças. ${ }^{15}$

Acompanhar o pai ou os irmãos mais velhos é uma atividade considerada prazerosa, conforme também constatado por Sousa (2004) a respeito da comunidade dos Capuxó da Paraíba, e da qual o garoto se orgulha. O orgulho deriva da participação em uma atividade familiar considerada importante, coisa de gente grande. Muitas vezes, a criança mais nova deseja contribuir para as atividades domésticas, mas os adultos dizem não porque ela é muito pequena. À medida que ela é requisitada para determinadas atividades, entende que está crescendo e sendo reconhecida como membro apto a contribuir para o bem-estar familiar. Além do orgulho relatado pelas crianças, há em muitos casos um sentimento de responsabilidade para com 
as atividades que lhe são destinadas, o que conta positivamente para a sua autoestima: trabalhando e cumprindo o seu dever, ela goza de um status diferenciado, sendo reconhecida pelos pais, irmãos e pela comunidade em geral como um(a) bom/boa filho(a).

Orgulho infantil e responsabilidade foram aspectos também mencionados por Morrow e Vennam (2010) e Sánchez (2007) a respeito do trabalho das crianças indianas e mexicanas, respectivamente. Dessa forma, é interessante observar, como fazem Libório e Ungar (2010), que algumas formas de trabalho infantil podem, na verdade e ao contrário do que se poderia imaginar, impactar positivamente o desenvolvimento psicossocial da criança, contribuindo, dentre outros aspectos, para a negociação de poder intrafamiliar, para o acesso a capital social e material e para um sentimento de bem-estar por parte das crianças.

Além dos benefícios que o trabalho pode trazer para a criança, como o aumento da autoestima, o sentimento de competência e o reconhecimento social e material (Morrow \& Vennam 2010; Libório \& Ungar 2010; Hungerland et al. 2007; Invernizzi 2007; Nieuwenhuys 1994), observei que algumas meninas se divertiam ao fazer serviços domésticos, principalmente quando umas estavam na casa das outras e quando eram ajudadas pelas amigas. ${ }^{16}$ Morton (1996) enfatiza este aspecto no que diz respeito ao trabalho realizado por meninos. Fortes (1938) dá inúmeros exemplos de como as crianças participam plenamente da sociedade talensi, inclusive da sua reprodução material, e comenta sua surpresa quando as crianças lhe disseram que preferiam trabalhar a brincar (1938:47). Eu ouvi o mesmo em Catingueira.

Para tentar entender esta assertiva, talvez precisemos pensar a questão do trabalho infantil e da ludicidade como atividades conjugadas. Nunes (2002) afirma que as crianças "brincam de fazer coisas de verdade", o que corrobora as minhas observações de campo, da mesma forma que as de Sousa (2004), em um contexto em que as crianças brincam e trabalham ao mesmo tempo. Fortes conclui que "[...] a cooperação da criança [...] inclui um elemento que emana da sua própria psicologia, a brincadeira". Essa capacidade de brincar enquanto se trabalha (ou estuda) é tido por Punch (2007) como uma forma de controle sobre o uso do tempo e do espaço por parte das crianças, a despeito da repressão adulta.

Embora as crianças assumam certas atividades desde muito jovens, é importante lembrar, como assinala Punch (2007:154), que a distribuição do trabalho doméstico, embora apresente algumas regularidades, é constantemente negociável entre os pais e as crianças e entre os irmãos e as irmãs: "Os pais dependem da ajuda das suas crianças e precisam da sua cooperação, mas isso tem que ser negociado". Além da negociação das atividades, 
as tarefas reservadas para a criança variam de acordo com a família. As que são maiores promovem uma distribuição mais ampla das tarefas. Famílias mais ricas podem postergar, reduzir ou extinguir o trabalho infantil doméstico. Uma família que valorize a educação formal ou que reconheça ter uma criança com talento para os estudos pode reduzir as tarefas pelas quais ela é responsável, a fim de incentivar as horas de dedicação à vida escolar.

Entretanto, há a crença geral de que as crianças devem começar a trabalhar desde cedo, uma vez que o trabalho tem um caráter educativo. Acredita-se que a criança que não ajuda os pais desde cedo tem grandes chances de se transformar em um adulto preguiçoso ou vagabundo e pouco qualificado para a vida, em outras palavras, um adulto que não sabe fazer nada. Uma moça que não saiba cozinhar e um rapaz sem disposição para o trabalho poderiam ser enquadrados nesta descrição. Há a convicção de que o trabalho, desde tenra idade, ajuda a formar uma pessoa de bom caráter. Assim, o trabalho infantil tem como objetivo educar a criança de acordo com um sistema moral, como lembra Mayblin $(2010: 220,226)$, destacando o seu papel educativo como forma de desenvolver a "coragem", característica moralmente apreciada em Santa Rita, Pernambuco. Já Sousa (2004) enfatiza o papel do trabalho infantil no processo de socialização das crianças: aquela que vai para a roça com o pai auxilia-o em algumas tarefas, mas sobretudo aprende que um homem deve ser trabalhador (a exemplo do seu pai), e não um preguiçoso. Dessa forma, o trabalho infantil está incluído em um sistema de educação moral, em que a disposição para o trabalho parece ser uma das principais características a serem aprendidas.

Em Catingueira, entende-se que o trabalho também tem como objetivo educar a criança para exercer atividades que serão essenciais a ela quando adulta. Se para o menino a disposição para o trabalho, exemplificada na "coragem para pegar qualquer serviço" disponível para sustentar a família, é a característica mais importante a ser aprendida, para uma menina, é a capacidade de gerência familiar e de organização doméstica. As redações de Leidiane, 12 anos, falam disso. Um pai exemplar é "uma pessoa [...] com coragem de lutar pela felicidade dos seus filhos e que pega qualquer serviço", e a mãe "gosta muito de fazer seus serviços de casa, como lavar roupa, arrumar, lavar louças, gosta muito do seu marido e dos seus filhos maravilhosos que eles têm". Estas características - coragem para o trabalho e talento como dona de casa — podem, em muitos casos, ser qualidades tão apreciadas quanto a educação formal. ${ }^{17}$

Isto é o que também afirmam Morrow e Vennam (2010:311) a respeito das meninas indianas, em Andhra Pradesh: "A mãe de Harika reconhece que enquanto as crianças devem ser educadas, as meninas, em particular, 
precisam desenvolver habilidades práticas para que possam administrar a casa com eficiência". Por isso, é importante que o curriculum escolar esteja atrelado às particularidades culturais da população para não incorrer no perigo de suprimir outras formas de aprendizado e competências importantes, como parece ter ocorrido na Libéria, segundo Lancy (1996).

Sánchez (2007:95) aponta que as razões do trabalho infantil devem ser entendidas a partir da "lógica interna da família camponesa", segundo a qual a reciprocidade entre gerações é um dos pilares da reprodução econômica e social. As crianças são alimentadas e cuidadas pelos seus pais e, em contrapartida, auxiliam nas tarefas necessárias, sendo consideradas essenciais no cuidado com os menos aptos a cuidarem de si mesmos, como as crianças pequenas e os idosos. Nesse sentido, devemos enfatizar os padrões de dependência intergeracionais que sustentam a casa sertaneja, na medida em que mostramos a importância das crianças na manutenção e na reprodução social e material das famílias. Ao mesmo tempo, entende-se por que o trabalho realizado pelas crianças na manutenção da sua unidade doméstica e os serviços prestados ao grupo familiar extenso ou à comunidade não são entendidos como exploração, mas sim como cooperação (Fortes 1938). Desta forma, esses trabalhos e serviços são tidos como "ajuda" e não "trabalho" propriamente, mas não são desvalorizados, como parece ser o caso do trabalho das mulheres em relação ao dos homens (Heredia 1979).

Um impasse parece estar colocado já que, do ponto de vista das instâncias governamentais e dos órgãos de defesa dos interesses da criança, o trabalho infantil é constantemente visto como prejudicial, sendo considerado o grande vilão em relação à escolarização das crianças (Hungerland et al. 2007). Todavia, desafiante é o paradoxo colocado por Edmonds (2007:28) quanto aos programas de incentivo à escolarização, na medida em que em alguns casos o tempo de lazer da criança é reduzido, mas suas horas de trabalho permanecem inalteradas. De fato, a não ser no caso do PETI, em que as crianças ficam na escola durante os dois turnos, aquelas que recebiam o benefício do programa Bolsa Escola em Catingueira não eram dispensadas das suas atividades domésticas. ${ }^{18} \mathrm{O}$ fato é que as crianças geralmente combinam trabalho e estudo e a "[...] escolarização não substitui o trabalho. Em casas camponesas pobres existe uma série de tarefas que permanecem sob a responsabilidade das crianças mesmo quando elas frequentam a escola" (Nieuwenhuys 1994:5).

Nesse sentido, é preciso indagar sobre os ganhos e os limites de políticas de erradicação de todas as formas de trabalho infantil, já que trabalho, lazer e escola são categorias complexas cujos significados variam enormemente de acordo com o grupo de interesse em questão (ONGs, Estado, famílias, Igreja, 
as próprias crianças etc.) (Morrow 2010; Wasiuzzaman \& Wells 2010; Edmonds 2007; Sousa 2004; Montgomery 2009; Qvortrup 2005). Ao mesmo tempo, é importante ressaltar, como faz grande parte da literatura sobre infância, a contribuição material do trabalho infantil para o orçamento familiar no sentido de uma adequação às condições adversas da pobreza. Embora não seja nosso foco nem o foco da população estudada, o trabalho infantil também responde a demandas econômicas (Montgomery 2009:151; Nieuwenhuys 1994) e, desta forma, concordamos com Fyfe quando afirma que o "[t]rabalho infantil é um assunto que diz respeito à pobreza e desigualdade" (1989:7). Todavia, Sánchez (2007:95) está correta quando esclarece que a pobreza não é "a principal razão por trás do trabalho das crianças" nas sociedades camponesas. ${ }^{19}$

Neste subtópico aprofundamos alguns dos trabalhos realizados e dos serviços prestados pelas crianças em Catingueira, compreendendo o trabalho como parte da infância, importante em um sistema de reciprocidade intergeracional da família camponesa, mas principalmente como um mecanismo de aprendizado moral, além de destacarmos a contribuição real feita pelas crianças para o bem-estar familiar e comunitário.

\section{Para terminar}

Neste artigo, através da inclusão das crianças como sujeitos na vida social catingueirense e, em consequência, como sujeitos aptos à pesquisa antropológica, a infância é compreendida etnograficamente como uma fase do aprendizado moral para o grupo. Uma criança aos 5 e 6 anos de idade ainda é objeto de apreciação, carinhos e motivo de risadas - embora, em comparação, menos que aos 3 ou 4 anos de idade. A redução deste tipo de tratamento vem junto com a constatação de que a criança começa a entender o mundo que a cerca. Ela deixa o estatuto de peça de entretenimento para passar a ser vista como um pequeno aprendiz. Este aprendizado é pensado a longo prazo e, por isso, não se exige demasiadamente de uma criança nesta idade. De acordo com o entendimento geral, ela está aprendendo, embora tanto as crianças quanto os outros membros familiares deem valor ao trabalho realizado, contribuindo para a autoestima e o bem-estar da criança. Como afirma Mayblin, " [...] as crianças são percebidas como se habitassem um estágio no qual sua prerrogativa é o aprendizado" (2010:157).

No entanto, a atividade que a criança executa é levada a sério, como assinalou Nunes (2002). Ela não está brincando de lavar a roupa, ela realmente lava a sua roupinha; nesse sentido, "[o] aprendizado da criança [...] é sempre socialmente produtivo", como deixa claro Fortes (1938:48). Se não 
fizer a atividade a ela reservada, certo desequilíbrio na organização doméstica vai ser criado e provavelmente um outro ajudante doméstico será requisitado (Nieuwenhuys 1994:17). Por fim, parece que o trabalho das crianças faz diferença na organização e no orçamento familiar catingueirense, uma vez que existem atividades consideradas exclusivamente infantis. Assim, podemos concordar que em Catingueira, assim como em Kano,

[...] Crescer não é uma transição entre ser um membro improdutivo da sociedade para se tornar um membro produtivo. [...] [A]s crianças participam de atividades social e economicamente significativas como crianças, gradualmente assumindo responsabilidades maiores e maior independência em relação aos seus pais (Schildkrout 1978:129).

A existência das crianças é pensada, em grande medida, como meio de suprir as necessidades e os desejos dos adultos, mais uma vez revelando padrões de dependência entre a geração mais velha e a geração mais nova, como enfatizado por Schildkrout (1978). Isto é constatado quando elas se transformam em objeto de divertimento das crianças maiores e dos adultos. Vimos também que os bebês estão à mercê dos caprichos das meninas préadolescentes que, apesar de serem responsáveis por pajeá-los, também se divertem à custa deste trabalho. Além disso, constatamos que as crianças servem aos adultos até quando morrem, já que um anjinho no céu resulta em proteção divina. Da mesma forma, as crianças tornam-se imprescindíveis na organização doméstica familiar de variadas maneiras. De outro lado, parece-me inútil centrar a análise na "exploração" das crianças pelos adultos, como o faz certa parte da literatura especializada - dado que essa mesma "exploração" (melhor seria dizer "participação") acaba por proporcionar uma tomada de poder pelas crianças, na medida em que elas se tornam agentes imprescindíveis para o bom funcionamento da unidade familiar e, de modo mais geral, de toda a comunidade.

Gostaria de terminar cotejando uma citação de Meyer Fortes:

Yindol, com cerca de apenas 11 anos de idade, um rapaz inteligente e empreendedor, já prestava assistência valiosa a seu pai, tanto no cuidado dos animais quanto na agricultura. Quando o grande baile estava se aproximando, Yindol quis uma tanga nova. Seu pai se recusou a comprar-lhe, foi quando Yindol entrou em greve, negligenciando as galinhas, os burros, as cabras e se recusou a capinar a roça, mesmo depois de uma surra. No final, seu pai teve de ceder. Bii la mar buurt - "O menino tem a justiça do seu lado" — disse ele, quando me contou a história (Fortes 1938:32). 
Flávia Pires é doutora em antropologia social pelo Museu Nacional, professora adjunta na Universidade Federal da Paraíba e atualmente visiting researcher no Centre for the Study of Children and Youth na University of Sheffield, Inglaterra. E-mail: <ffp23279@gmail.com>

\section{Notas}

Uma dívida profunda é reconhecida ao professor Otávio Velho e também às professoras Christina Toren e Léa Freitas Perez pelas inestimáveis contribuições ao meu trabalho. Agradeço ao Antonio Luiz da Silva, à Maya Mayblin e à Christiane Falcão pela leitura das primeiras versões do manuscrito e aos catingueirenses, crianças e adultos, que tornaram possível o meu trabalho.

${ }^{1}$ Embora o conceito de desterritorização de Deleuze e Guattari não se restrinja aos deslocamentos geográficos, como foi adequadamente pontuado pelo parecerista anônimo da revista Mana, no caso dos jovens catingueirenses que migram em busca de melhores condições de vida, o conceito pode ser utilizado na medida em que é, precisamente, através desse processo que eles conseguem traçar "linhas de fuga" da realidade pouco atraente da sua cidade. A migração, no entanto, não encerra as relações sociais e familiares baseadas na terra natal, mas as reconfigura de modo positivo, através das visitas durante as festas da cidade e o envio de remessas financeiras.

${ }^{2}$ Ignorante desta regra, sempre elogiava sobremaneira os dons culinários da cozinheira e o sabor da comida, quando era convidada para o almoço ou o jantar. Comecei a perceber, aos poucos, certo constrangimento quando o fazia, e só muito depois fui entender a razão pela qual os elogios não são em geral bem vindos. Da mesma forma, uma mãe não espera ouvir elogios quanto à beleza ou à inteligência de um filho. Curiosamente, até mesmo uma mãe pode colocar mau-olhado no seu bebê. Ouvi uma mãe dizer, sorrindo, que tinha medo de colocar mau-olhado no seu próprio filho pelo fato de amá-lo demasiadamente. Sobre o mau-olhado, o olho mau ou ruim, vide Otavio Velho (1995:23).

${ }^{3}$ De modo geral, às visitas importantes ou bem-vindas são oferecidos doce e/ou café. O doce é sempre acompanhado de um copo de água — de preferência, gelada. É comum ouvir: "vou comer um doce para tomar água" ou "come um doce para tomar água". Os doces muito apreciados na região são o doce de leite, de gergelim e de frutas como manga ou mamão verde, que podem ser cozidos com açúcar ou rapadura. 
${ }^{4}$ No próximo subtópico apresentarei os trabalhos domésticos realizados pelas crianças e que são divididos por gênero.

${ }^{5}$ Todas as traduções ao longo do artigo são de minha autoria.

${ }^{6}$ Aspecto também encontrado em Schildkrout (1978:122) e Morton (1996).

${ }^{7}$ Exceto quando não foi batizada, segundo os católicos. Porém, o batismo também pode ser realizado pós-morte, restaurando o equilíbrio necessário para a aceitação daquela alma no céu.

${ }^{8}$ No caso de famílias consideradas ricas, a roupa também pode ser lavada no açude, mas o serviço será contratado de outra mulher fora do círculo familiar.

${ }^{9}$ Obviamente, quando a casa não é de piso de barro.

${ }^{10}$ O Programa Bolsa Família parece ter tido um impacto importante para assegurar o acesso à alimentação das famílias, de forma que, hoje em dia, essa realidade felizmente não é a regra (Pires 2009).

${ }^{11}$ Diria que comer é uma atividade reservada, feita no íntimo da família, no ambiente da casa mais distante da porta da rua. Não se come nas ruas, assim como não se oferece comida para os visitantes assim que eles chegam a casa. Há que ser visita íntima ou importante para ser convidado a tomar parte à mesa nas refeições.

${ }^{12}$ Muitas vezes ouvi donas de casa desculpando-se por não poderem ficar de bate-papo com as vizinhas porque tinham "muita luta lá dentro!". Sobre o "idioma do sofrimento" e como ele está ligado ao que define moralmente uma boa mulher, veja Mayblin (2010:68-93).

${ }^{13}$ A idade para começar a frequentar a escola pode variar entre 5 e 7 anos, de acordo com o nível de conhecimento formal que a criança apresente. No entanto, essa flexibilidade quanto à idade de entrada na escola parece ter sido alterada com os programas de incentivo à escolarização, como o Bolsa Escola e o Bolsa Família, que condicionam a frequência escolar ao recebimento da transferência de renda.

${ }^{14} \mathrm{O}$ que também foi destacado por Schildkrout a respeito da zona urbana de Kano (Schildkrout 1978:126).

${ }^{15}$ O papel da observação no aprenzidado foi destacado por Fortes (1938) e Morton (1996).

${ }^{16}$ As meninas de variadas idades muito constantemente pediam para arrumar a minha casa e lavar as minhas vasilhas. Algumas delas disseram-me que gostavam mais de fazer o serviço da casa que de desenhar ou ir para o colégio. Sentia-me incomodada de vê-las trabalhando na minha casa, mas elas insistiam para que as deixasse fazerem as tarefas. Algumas vezes deixei. Outras, quando fazíamos alguma refeição 
juntas, tão logo acabávamos, elas se levantavam da mesa e iam direto para a pia lavar as vasilhas. Faziam como que automaticamente e sem o mínimo constrangimento. Às vezes, eu dizia "não", e elas vinham com uma ladainha de porquês. E pediam que as deixasse fazer, que elas gostavam, que elas queriam... Argumentava que já as tinha ouvido reclamando do serviço da casa. Elas replicavam, dizendo que queriam fazer porque era na minha casa e para mim. O fato pode ser parcialmente entendido se pensarmos que, em relação a uma parenta por volta dos 20 anos, o dever de lavar as vasilhas será da menina mais nova que more na mesma residência — porque a atividade é tida como fácil dentre os outros serviços domésticos. E, neste caso, fui colocada no papel de mulher mais velha. Mas há outras considerações a fazer. Um fato é que a casa desarrumada e as louças por lavar depositadas na pia depõem contra a dona da casa - e, talvez, elas zelassem pela minha imagem social. Outra razão é que na minha casa os serviços domésticos eram feitos de maneira diferente da maioria das casas da cidade e, com isso, talvez para elas, o serviço parecesse divertido. Eu lavava os "troços" na pia, ao invés de utilizar a torneira perto do chão do lado de fora da casa. E usava detergente líquido, e não sabão. As meninas sempre se mostravam prestativas quando era hora de varrer a casa e passar o pano. Em muitas casas, no entanto, não se passa o pano molhado, porque o chão é de barro. É interessante citar que essas meninas varrem o chão de barro da sua casa de cócoras, com o auxílio de ramos de massambê que, juntos, dão a forma de uma vassoura, mas sem o cabo. Na minha casa, o chão de cerâmica era limpo com um rodo e um pano molhado. Não foram apenas as crianças que me ofertavam ajuda doméstica. As mocinhas e as moças também se ofereciam para me ajudar na lida, ou "luta", da casa. Uma delas, de 15 anos, sempre me dizia que mandasse chamá-la quando fosse lavar a casa. As moças da minha idade também tinham atitudes parecidas e uma, em especial, oferecia-se para lavar minhas peças de roupa grandes no açude. De tudo isso, gostaria de ressaltar que há certa dose de diversão envolvida nos serviços domésticos, principalmente se a atividade é feita com a ajuda das amigas, o que não é incomum. Nesse momento, as meninas se divertem. Conversam, riem muito, escutam música e dançam. As mães, no entanto, geralmente reclamam da arrumação coletiva, dizendo que elas demoram muito tempo, e que o serviço fica mal feito. No entanto, para Fortes as crianças identificam-se com os adultos e é por isso que preferem trabalhar a brincar: "[...] todas as crianças tale querem crescer. Eu sempre perguntava aos meninos de 10 a 12 anos por que eles estavam tão interessados na capina, embora fosse muito mais árdua do que o pastoreio ou a brincadeira com seus amigos. A pergunta intrigava muitos, embora eles sempre fossem enfáticos sobre a preferência do trabalho na fazenda ao pastoreio ou à brincadeira" (1938:47).

${ }^{17}$ Assim, o Programa Bolsa-Escola tentou contornar o fato ao garantir um "salário" para a criança, acabando por forçar a educação formal, mesmo em famílias nas quais ela não seria prioritária (Pires 2009).

${ }^{18}$ A criança que frequenta o PETI, no entanto, pode ser mais facilmente dispensada de todo o trabalho doméstico, porque o estudo, nestas condições (em dois turnos), é considerado por demais estafante. O seu tempo livre é dedicado à diversão, no qual brincar na rua com os colegas e vizinhos e "assistir" [televisão] parecem ser as atividades preferidas. 
${ }^{19}$ Mas mesmo que nem todos os trabalhos infantis sejam prejudiciais, de fato abusos ocorrem e devem ser punidos. São relevantes os esforços empreendidos pela sociedade brasileira, pelo Estado e pelos organismos mundiais para banir aquelas que são consideradas as "piores formas de trabalho infantil", o que inclui escravidão, prostituição, trabalho em conflito armado e no tráfico de drogas, por exemplo.

\section{Referências bibliográficas}

CLIFFORD, James. 1998. A experiência etnográfica: antropologia e literatura no século XX. Rio de Janeiro: Editora UFRJ.

COHN, Clarice. 2000. "Crescendo como um Xikrin: uma análise da infância e do desenvolvimento infantil entre os Kayapó-Xikrin do Bacajá". Revista de Antropologia, 43(2):195-222.

DELEUZE, Gilles \& GUATTARI, Félix. 1995-1997. Mil platôs. Capitalismo e esquizofrenia. Rio de Janeiro: Editora 34.

EDMONDS, E. V. 2007. Children labour. Cambridge, MA: National Bureau of Economic Research.

INVERNIZZI, Antonella. 2007. "Children's work as 'participation': thoughts on ethnographic data in Lima and Algarve". In: Beatrice Hungerland; Manfred Liebel; Brian Milne \& Anne Wihstutz (orgs.), Working to be someone - child focused research and practice with working children. London and Philadelphia: Jessica Kingsley Publishers. pp. 135-144.

FYFE, Alec. 1989. Child labour. Cambridge: Polity Press.

FORTES, Meyer. 1938. "Social and psychological aspects of education in Taleland". Supplement to Africa, XI(04): 1-64.
HEREDIA, Beatriz M. A. 1979. A morada da vida: trabalho familiar entre pequenos produtores do Nordeste do Brasil. 1a. ed. Rio de Janeiro: Paz e Terra.

HUNGERLAND, Beatrice; LIEBEL, Manfred; MILNE, Brian \& WIHSTUTZ, Anne. 2007. Working to be someone - child focused research and practice with working children. London and Philadelphia: Jessica Kingsley Publishers.

LANCY, David. 1996. Playing on the mother-ground. Cultural routines for children's development. New York: Guilford Press.

LÉVI-STRAUSS, Claude. 1952. Raça e história. Lisboa: Editora Presença, LDA.

LIBÓRIO, Renata M. C. \& UNGAR, Michael. 2010. "Children's perspectives on their economic activity as a pathway to resilience". Children \& Society, 24(4):326-338.

MAUSS, Marcel. 2003 [1950]. "Ensaio sobre as variações sazoneiras das sociedades esquimó". In: Sociologia e antropologia. São Paulo: Cosac \& Naify. pp. 423-505.

MAYBLIN, Maya. 2010. Gender, catholicism and morality in Brazil. Virtuous husbands, powerful wives. New York: Palgrave / Macmillan.

MEAD, Margaret \& BATESON, Gregory. 1942. Balinese character: a photo- 
graphic analysis. New York: New York Academy of Sciences.

MORTON, Helen. 1996. Becoming a Tongan. An ethnography of childhood. Honolulu: University of Hawai'i Press.

MONTGOMERY, Heather. 2009. An introduction to childhood. Anthropological perspectives on children's lives. Oxford: Wiley-Blackwell.

MORROW, Virginia \& VENNAM, Uma. 2010. "Combining work and school: the dynamics of girl's involvement in agricultural work in Andhra Pradesh, India". Children \& Society, 24(4): 303-314.

MORROW, Virginia. 2010. "Should the world be really free of "child labour'? Some Reflections". Childhood, 17(4):435-440.

NIEUWENHUYS, Olga. 1994. Children's lifeworlds. Gender, welfare and labour in the development world. London and New York: Routledge.

NUNES, Angela. 2002. "No tempo e no espaço: brincadeiras das crianças A'uwe-Xavante". In: Aracy Lopes da Silva; Angela Nunes \& Ana Vera Macedo (orgs.), Crianças indígenas: ensaios antropológicos. São Paulo: Global. pp. 64-100.

PIRES, Flávia Ferreira. 2003. Os filhosausentes e as penosas de São Sebastiãozinho. Etnografia da Festa da Catingueira/PB. Dissertação de Mestrado. PPGAS/MN/UFRJ. 2007. "Ser adulta e pesquisar crianças: explorando possibilidades metodológicas na pesquisa antropológica". Revista de Antropologia, 50:225-270.

2008. "Cidade, casa e Igreja: sobre Catingueira, seus adultos e suas crianças". Campos, 8(2):65-79. 2009. "A casa sertaneja e o Programa Bolsa-Família: questões para pesquisa". Política \& Trabalho, 27:1-12.
- 2010. "Tornando-se adulto: uma abordagem antropológica sobre crianças e religião". Relig. Soc. [online], 30(1): 143-164.

- 2011a. Quem tem medo de mal-assombro? Religião e infância no semiárido nordestino. Rio de Janeiro/ João Pessoa: E-Papers/ UFPB.

— 2011b. "A Festa de São Sebastião em Catingueira: dez anos depois". Revista de Antropologia, 54:1051-1076.

PUNCH, Samantha. 2007. "Generational power relations in rural Bolivia". In: Ruth Panelli; Samantha Punch \& Elsbeth Robson (orgs.), Global perspectives on rural childhood and youth. New York: Routledge. pp. 151-164.

QVORTRUP, Jens. 2005 (ed.). Studies in modern childhood. Society, agency and culture. Hampshire/ New York: Palgrave Macmillan.

SÁNCHEZ, Martha Areli Ramírez. 2007. '“'Helping at home': the concept of childhood and work among the Nahuas of Tlaxcala, Mexico". In: Beatrice Hungerland; Manfred Liebel; Brian Milne \& Anne Wihstutz (orgs.), Working to be someone - child focused research and practice with working children. London and Philadelphia: Jessica Kingsley Publishers. pp. 87-95.

SCHEPER-HUGHES, Nancy. 1992. Death without weeping: the violence of everyday life in Brazil. Berkeley: California University Press.

SCHILDKROUT, Enid. 1978. "Age and gender in Hausa society: socio-economic roles of children in urban Kano". In: J. S. La Fontaine (ed.), Age and sex as principles of social differentiation. London: Academic Press. pp. 109-137.

SOUSA, Emilene Leite de. 2004. "Que trabalhais como se brincásseis": trabalho e ludicidade na infância capuxu. Dissertação de Mestrado em Ciências 
Sociais, Universidade Federal de Campina Grande, Paraíba.

TOREN, Christina. 1999. Mind, materiality and history. Explorations in fijian ethnography. London and New York: Routledge.

· 2010. "A matéria da imaginação: o que podemos aprender com as ideias das crianças fijianas sobre suas vidas como adultos". Horizontes Antropológicos, 16(34):19-48.

. 2002. "Anthropology as the whole science of what it is to be human". In: Richard G. Fox \& Barbara J. King (orgs.), Anthropology beyond culture. Oxford and New York: Berg. pp. 105-124.

VELHO, Otavio. 1995. Besta Fera: recriação do mundo. Rio de Janeiro: RelumeDumará.

WASIUZZAMAN, Shaziah \& WELLS, Karen. 2010. "Assembling webs of support: child domestic workers in India". Children \& Society, 24(4):282-292. 


\section{Resumo}

Este artigo etnográfico tem como objetivo apresentar as crianças catingueirenses (semiárido da Paraíba), destacando sua participação na vida social e familiar, através do desvelamento das contingências cotidianas que enfrentam, assim como as expectativas adultas em relação a elas. Para isso, minha estratégia é, através de três memórias etnográficas - um evento na igreja envolvendo uma criança de 3 anos, o ritual de apresentação dos novos membros à comunidade e um cortejo fúnebre de um anjinho - pensar as crianças pequenas como risíveis, as crianças maiores como aprendizes e a infância como período de trabalho e de aprendizado moral. O texto revela um universo em que as crianças se tornam agentes imprescindíveis para o bom funcionamento da unidade familiar e, de modo mais geral, de toda a comunidade.

Palavras-chave Criança, Infância, Trabalho infantil, Socialização, Família, Campesinato.

\section{Abstract}

The focus of the present article is ethnographic, aiming to describe the children of the catingueira (a semiarid region in Paraíba state), highlighting their participation in social and family life. I reveal the contingencies these children face an daily life as well as adults' expectations regarding them, focusing on three ethnographic memories: an event in church involving a three year old child; the ritual presentation of new members to the community and a funeral procession for a "little angel" (a dead child). Here I propose to think of small children as laughable, of older children apprentices and of childhood as a period of work and moral learning. The text reveals a universe in which children become agents who are essential for the proper functioning of the family unit and, more generally, of the whole community.

Key words Children, Infancy, Child labor, Socialization, Family, Peasantry. 